\title{
ARTICLE
}

\section{Tunneling Effects in Confined Gold Nanoparticle Hydrogenation Catalysts}

Received 00th January 20xx, Accepted 00th January 20xx DOI: $10.1039 / \times 0 \times x 00000 x$

\begin{abstract}
Leandro Luza, ${ }^{\text {*a }}$ Aitor Gual, ${ }^{\mathrm{b}}$ Jesum Fernandes, ${ }^{c}$ Dario Eberhardt, ${ }^{\mathrm{d}}$ and Jairton Dupont*a
Clean surface gold $\sim 6.6 \mathrm{~nm}$ nanoparticles (AuNPs) that were confined in ionic liquid (IL) cages of hybrid $\gamma$-alumina $\left(\gamma\right.$ - $\mathrm{Al}_{2} \mathrm{O}_{3}$ ) displayed hydrogenation pathways in the reduction of trans-cinnamaldehyde distinct from those imprinted directly onto $\gamma$ $\mathrm{Al}_{2} \mathrm{O}_{3}$. Hydrogen activation proceeded via homolytic activation in IL-encapsulated AuNPs and by heterolytic cleavage for ILfree supported AuNPs. Higher negative apparent entropy $\left(\Delta S_{\text {app }}\right)$ values were obtained for the IL-confined AuNPs compared to the non-hybrid catalyst $\left(\mathrm{Au} / \mathrm{\gamma}-\mathrm{Al}_{2} \mathrm{O}_{3}\right)$, suggesting a decrease in the number of microstates induced by the nano-confined environment. High kinetic isotope effect $(\mathrm{KIE})$ values $\left(k_{\mathrm{H}} / k_{\mathrm{D}}=2.5-2.9\right.$ at $\left.273 \mathrm{~K}\right)$ and Arrhenius convex curves were observed. Furthermore, differences of 5.6 and $6.2 \mathrm{~kJ} \mathrm{~mol}^{-1}$ between the apparent activation energies of the deuteration and hydrogenation reactions $\left(E_{\mathrm{a}-\mathrm{app}}{ }^{\mathrm{D}}-E_{\mathrm{a}-\mathrm{app}}{ }^{\mathrm{H}}\right)$ associated with the pre-exponential factors ratios $\left(A^{\mathrm{D}} / A^{\mathrm{H}}\right)$ of 4.6 and 5.1 provided strong evidence of the possible involvement of a tunneling pathway in the case of the confined AuNPs.
\end{abstract}

\section{Introduction}

The introduction of a confined space around an active catalytic site could be a practical way to produce unusual activities and selectivities in transition metal catalysts. ${ }^{1}$ These encapsulated catalysts can change certain steps in the catalytic cycle, giving rise to new kinetic profiles and altered selectivities, thereby inducing shape-substrate selectivity. ${ }^{2}$ In particular, metal nanoparticles (MNPs) supported in bare ionic liquids (ILs) or IL hybrid materials displayed catalytic properties of nanoconfined devices. ${ }^{3,4}$ In these restricted nano-environments, the number of microstates may change under asymmetric dynamic conditions (metal catalyst/ligand/support/reagent/product). Furthermore, the reaction could proceed far from equilibrium ${ }^{5}$ ${ }^{6}$ and exhibit various phenomena of temporal and spatial selforganization ${ }^{7}$ and complex transitory structures. ${ }^{8}, 9$ For example, for catalytic hydrogenation over NPs@ILs, curved Arrhenius plots and relative high kinetic isotope effects (KIEs) are usually obtained, which might also suggest the involvement of a tunneling pathway. ${ }^{10-13}$

The term "tunneling control" denotes a reaction that passes through a high but narrow potential energy barrier, leading to the formation of a product that would be disfavored if the reaction proceeded by passage over kinetic barriers rather than

a. Laboratory of Molecular Catalysis, Universidade Federal do Rio Grande do Sul, Av. Bento Gonçalves, 9500, Porto Alegre, Brazil.

b. Unitat de Tecnología Química (UTQ)-EURECAT, Centre Tecnològic de la Química de Catalunya (CTQC), c/ Marcel.lí Domingo, s/n, Building N5, Tarragona 43007, Spain. c. School of Chemistry, University of Nottingham, NG7 2RD, Nottingham, UK.

d.PUCRS, Centro Interdisciplinar de Nanociências e Micro-Nanotecnologia, Av. Ipiranga, 6681, Porto Alegre, Brazil.

Electronic Supplementary Information (ESI) available: characterization of the

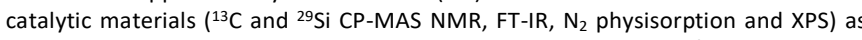
well as the kinetic and isotopic experiments $\left({ }^{1} \mathrm{H}\right.$ and ${ }^{2} \mathrm{H}$ NMR). See DOI: $10.1039 / x 0 \times x 00000 x$ through them. This reactivity paradigm should be considered in addition to thermodynamic and kinetic control as a factor that can determine which of two or more possible products is likely to be obtained. ${ }^{10}$ Hydrogen tunneling plays an important role in chemical reactivity at room temperature in biochemistry, organic chemistry, and catalysis. The tunneling effect is mainly recognized based on kinetic isotope effect measurements, and it is known that the chemical environment, particularly in enzymatic catalysis, affects tunneling by the vibration of enzymes, which compresses reaction barriers at the active site. ${ }^{14}$

Therefore, NPs@ILs may constitute an adequate model to investigate the possible contribution of the tunneling effect in hydrogenation reactions over these metal surfaces. For this reason, clean-surfaced, small, and well-distributed AuNPs supported directly on $\gamma$-alumina $\left(\gamma-\mathrm{Al}_{2} \mathrm{O}_{3}\right)$ and on IL-hybrid $\gamma$ $\mathrm{Al}_{2} \mathrm{O}_{3}$ were prepared (Scheme 1 ). In addition, detailed kinetic

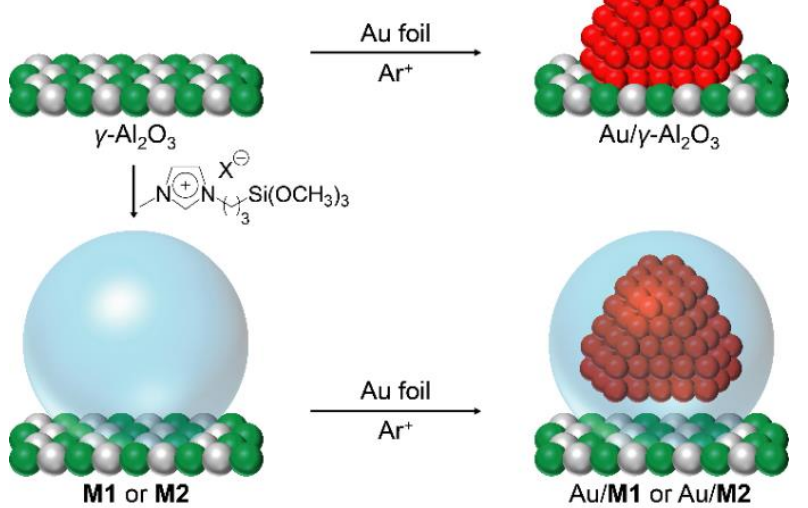

Scheme 1. Au nanocatalysts prepared by sputtering deposition: $\mathrm{Au} / \mathrm{\gamma}-\mathrm{Al}_{2} \mathrm{O}_{3}, \mathrm{Au} / \mathrm{M} \mathbf{1}$ (X: $\mathrm{Cl})$, and $\mathrm{Au} / \mathrm{M} 2\left(\mathrm{X}: \mathrm{NTf}_{2}\right)$. Adapted from reference 18. 
and isotopic experiments of the selective hydrogenation of trans-cinnamaldehyde (1) have offered a significant indication that, in these confined spaces (IL cages), a tunneling mechanism could be operative. This is because the Arrhenius plots have exhibited convex curves, and the primary isotope effect was larger than 2.5 when calculated from equations based on semiclassical models and transition-state theory. Additionally, the differences between the apparent activation energies of the deuteration and hydrogenation reactions $\left(E_{\mathrm{a}-\mathrm{app}}{ }^{\mathrm{D}}-E_{\mathrm{a}-\mathrm{app}}{ }^{\mathrm{H}}\right)$ were significantly above $5 \mathrm{~kJ} \mathrm{~mol}^{-1}$, and, finally, pre-exponential factors ratios $\left(A^{\mathrm{D}} / A^{\mathrm{H}}\right)$ were larger than $2 .{ }^{12,13,15}$

\section{Results and Discussion}

The IL-hybrid $\gamma-\mathrm{Al}_{2} \mathrm{O}_{3}$ supports $\mathbf{M} \mathbf{1}$ and $\mathbf{M} \mathbf{2}$ were prepared by the reaction of hydroxyl groups of the $\mathrm{\gamma}-\mathrm{Al}_{2} \mathrm{O}_{3}$ surface with 1methyl-3-(trimethoxysilylpropyl)-imidazolium chloride and by simple M1 anion exchange with LiNTf ${ }_{2}$, respectively (Scheme 1). ${ }^{16,17}$ All supports were decorated with AuNPs using a 3D mixing-sputtering device (Scheme 1) and characterized by ${ }^{13} \mathrm{C}$ and ${ }^{29} \mathrm{Si}$ solid-state cross-polarization magic angle spinning nuclear magnetic resonance (CP-MAS NMR), Fourier transform infrared (FT-IR), N2-physisorption, X-ray fluorescence (XRF), Rutherford backscattering spectrometry (RBS), X-ray diffraction (XRD), and transmission electron microscopy (TEM) (see ESI: Section S1, Figures S1-S9, and Tables S1-S4). It is worth mentioning that the AuNP surfaces were completely composed

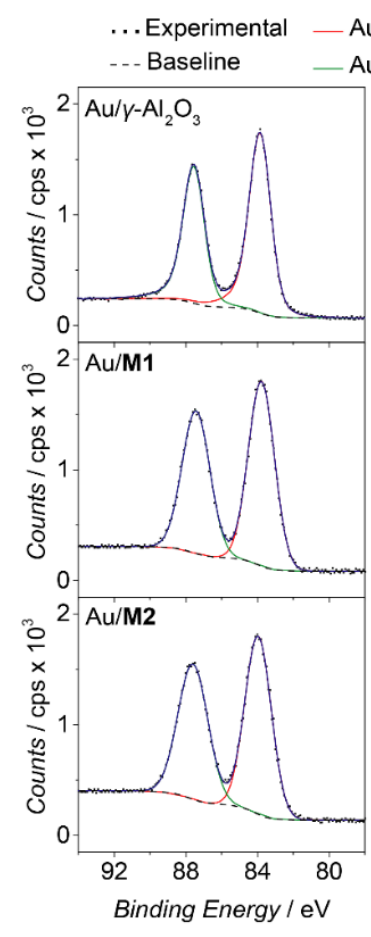

(a)

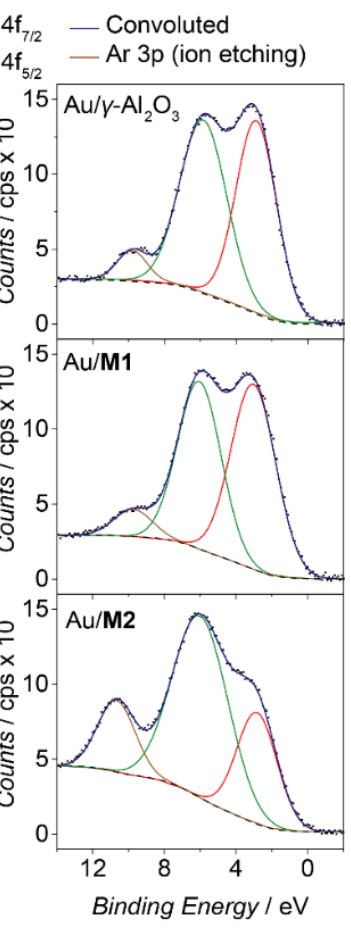

(b)
Figure 1. XPS measurements at (a) $A u 4 f$ and (b) at Au valence band regions on the $A u / \gamma$ $\mathrm{Al}_{2} \mathrm{O}_{3}, \mathrm{Au} / \mathrm{M} 1$, and $\mathrm{Au} / \mathrm{M} 2$ catalysts.

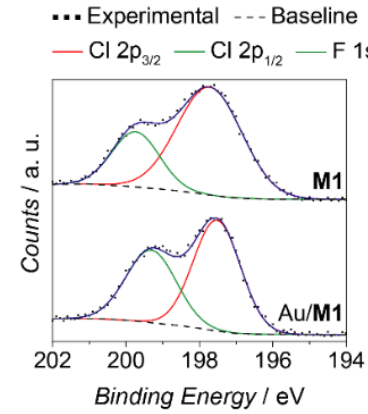

(a)

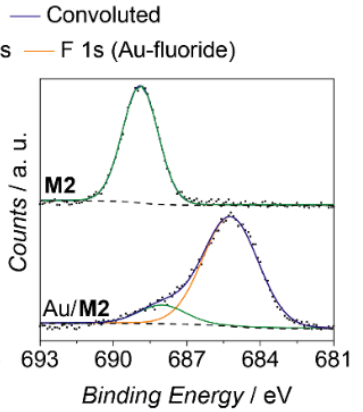

(b)
Figure 2. XPS spectra at (a) the $\mathrm{Cl}$ region of the $\mathbf{M} 1$ support and $\mathrm{Au} / \mathrm{M} 1$ catalyst and (b) the $\mathrm{F}$ region of the $\mathbf{M} \mathbf{2}$ support and $\mathrm{Au} / \mathbf{M} \mathbf{2}$ catalyst.

of metallic gold $\left(\mathrm{Au}^{0}\right)$ for all catalysts (Figure 1a), as determined by X-ray photoelectron spectroscopy (XPS), with a slight positive shift for Au binding energies ( $4 \mathrm{f}$ and valence band) in $\mathrm{Au} / \mathrm{\gamma}-\mathrm{Al}_{2} \mathrm{O}_{3}$ with respect to $\mathrm{Au} / \mathbf{M} 1$ and $\mathrm{Au} / \mathrm{M} 2$ (Figure $1 \mathrm{~b}$ and Table S5 in the ESI). This fact suggests that the interaction of the AuNPs with the $\gamma-\mathrm{Al}_{2} \mathrm{O}_{3}$ support decreased due to the IL pair layers, which formed an IL cage surrounding the AuNPs. ${ }^{18-21}$ Moreover, a slight negative shift of $0.6 \mathrm{eV}$ in the $\mathrm{Cl} 2 \mathrm{p}$ region of $\mathrm{Au} / \mathrm{M} 1$ was noted (197.9 and $197.3 \mathrm{eV}$ for M1 and Au/M1, respectively) (Figure 2). In the case of $\mathrm{NTf}_{2}$-bearing supports, the $\mathrm{F} 1 \mathrm{~s}$ regions of $\mathbf{M} 2$ and $\mathrm{Au} / \mathbf{M} \mathbf{2}$ displayed a peak related to uncoordinated $\mathrm{NTf}_{2}$ anion (688.9 and $688.1 \mathrm{eV}$, respectively), and a new component appeared at $684.9 \mathrm{eV}$ only for $\mathrm{Au} / \mathrm{M} 2 .^{22}$ These behaviors, assigned to the interaction of the contact ion pairs with the AuNPs. ${ }^{23,24}$

The kinetics of the hydrogenation and deuteration of $\mathbf{1}$ were explored using a modified Langmuir-Hinshelwood model (see ESI, Section S2, Tables S6-S8) with an overall rate law expressed as:

$$
r_{\mathrm{x}}=\frac{k_{\mathrm{x}} K_{1-\mathrm{x}}[1]\left[{ }^{*}\right]_{0}}{1+K_{1-\mathrm{x}}[1]} \quad \text { (1) }(\text { with } \mathrm{x}=\mathrm{H} \text { or } \mathrm{D})
$$

Different reaction rate constants $\left(k_{x}\right)$ (Table 1 and Figure 3) provided distinct KIE values for the Au nanocatalysts confined in the IL when applied at temperatures between 273 and $423 \mathrm{~K}$ (Table 2).

Table 1. Reaction rate constants of the hydrogenation and deuteration of 1 catalyzed by $\mathrm{Au} / \mathrm{V}-\mathrm{Al}_{2} \mathrm{O}_{3}, \mathrm{Au} / \mathrm{M} 1$, and $\mathrm{Au} / \mathbf{M} 2$ at different temperatures.

\begin{tabular}{ccccc}
\hline & \multicolumn{4}{c}{$k_{\mathrm{H}}$ and $k_{\mathrm{D}} / \mathrm{mmol} \mathrm{m}^{-2} \mathrm{~h}^{-1[\mathrm{~b}]}$} \\
\cline { 3 - 5 } Entry $^{[\mathrm{a}]}$ & $\mathrm{T} / \mathrm{K}$ & $\mathrm{Au} / \mathrm{H}^{-\mathrm{Al}_{2} \mathrm{O}_{3}}$ & $\mathrm{Au} / \mathrm{M} 1$ & $\mathrm{Au} / \mathrm{M} 2$ \\
\hline 1 & 273 & 23 and 18 & 5 and 2 & 5 and 1.7 \\
2 & 323 & 83 and 72 & 59 and 30 & 46 and 23 \\
3 & 348 & 176 and 139 & 221 and 158 & 144 and 89 \\
4 & 373 & 332 and 219 & 352 and 239 & 233 and 156 \\
5 & 423 & 777 and 599 & 756 and 542 & 509 and 377 \\
\hline
\end{tabular}

[a] Reaction conditions: $\mathrm{Au}(0.5 \mu \mathrm{mol}), 1 / \mathrm{Au}=250-4000$, anisole $(10 \mathrm{~mL}), 2.5 \mathrm{MPa}$ of $\mathrm{H}_{2}$ or $\mathrm{D}_{2}$, and $250 \mathrm{rpm}$; ${ }^{[b]}$ Analyzed by gas chromatography $(\mathrm{GC})$ and calculated using a modified Langmuir-Hinshelwood model at conversions of approximately $5 \%$ from the slope of reaction rate vs. time. ${ }^{25,26}$ 


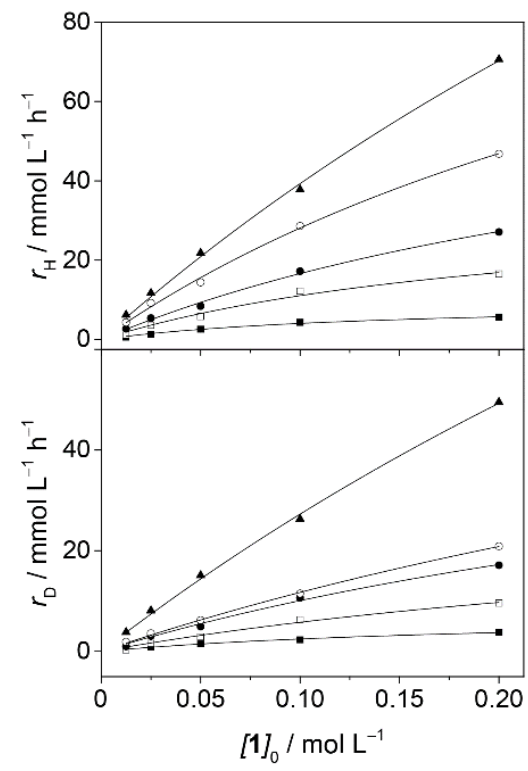

(a)

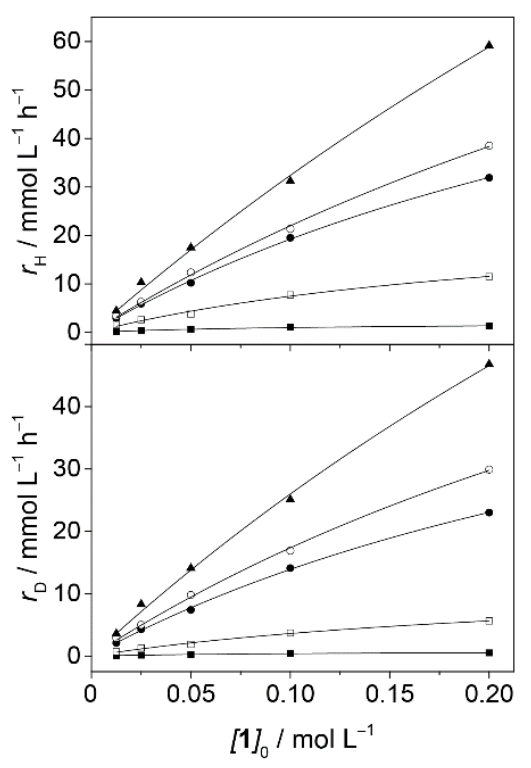

(b)

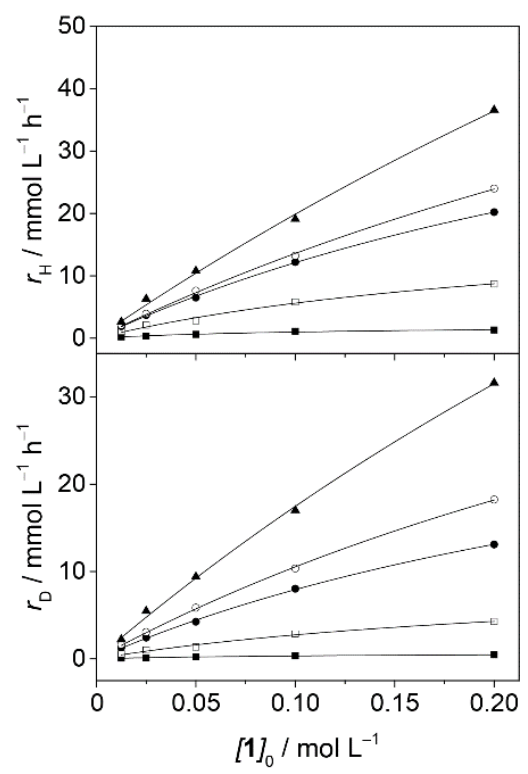

(c)

Figure 3. Hydrogenation and deuteration rate dependence on $\mathbf{1}$ concentrations catalyzed by (a) $\mathrm{Au} / \mathrm{Y}-\mathrm{Al}_{2} \mathrm{O}_{3}$, (b) $\mathrm{Au} / \mathbf{M 1}$, and (c) $\mathrm{Au} / \mathbf{M} \mathbf{2}$ at temperatures of $273 \mathrm{~K}(-\mathbf{m}-)$, $323 \mathrm{~K}(-\square-), 348 \mathrm{~K}(-\bullet-), 373 \mathrm{~K}(-0-)$, and $423 \mathrm{~K}(-\mathbf{\Delta}-)$.

A KIE value of 1.3 was observed over the entire temperature range for the $\mathrm{Au} / \mathrm{V}-\mathrm{Al}_{2} \mathrm{O}_{3}$ catalyst (Table 2 , entry 1 ), which is comparable to values observed in a previous work using $\mathrm{Au} / \mathrm{Y}$ $\mathrm{Al}_{2} \mathrm{O}_{3}$ in the hydrogenation of dienes to monoenes $\left(k_{\mathrm{H}} / k_{\mathrm{D}}=\right.$ 1.1 $)^{18}$ and similar to those observed in the hydrogenation reactions using $\mathrm{Au} / \mathrm{TiO}_{2},{ }^{27} \mathrm{Pd} / \mathrm{Al}_{2} \mathrm{O}_{3},{ }^{17} \mathrm{Pd} / \mathrm{SiO}_{2},{ }^{19}, 28$ and $\mathrm{Pd} / \mathrm{C}^{29}$ $\left(k_{\mathrm{H}} / k_{\mathrm{D}}=1.3-1.6\right)$ catalysts. Consequently, it is suggested that $\mathrm{H}_{2} / \mathrm{D}_{2}$ activation is not the rate-determining step (RDS) of the hydrogenation reactions catalyzed by $\mathrm{Au} / \mathrm{\gamma}-\mathrm{Al}_{2} \mathrm{O}_{3}$. In contrast, higher KIEs were obtained as the reaction temperature decreased, from 1.4 and 1.3 at $423 \mathrm{~K}$ to 2.5 and 2.9 at $273 \mathrm{~K}$, by the IL-hybrid Au/M1 and Au/M2 catalysts, respectively (Table 2, entries 2 and 3), which points to a different reaction pathway in these cases. This scenario is akin to that of micelle nano (macro)reactors, compartmentalizing and concentrating/separating reactants and hence altering the apparent rate and equilibrium constants. ${ }^{30}$

At $273 \mathrm{~K}$, the selectivity to hydrocinnamaldehyde (2) was essentially the same ( 97\%) for all catalysts, whereas the deuterated $\mathbf{2}-\mathbf{d}_{\mathbf{2}}$ product underwent changes depending on the catalyst used (Table 3). Higher selectivities for $\mathbf{2}-\mathbf{d}_{\mathbf{2}} \mathbf{2 , 3}$ (72\%) indicate preference for 1,2-addition at the carbonyl group $(C=O)$, followed by isomerization of the deuterated cinnamyl alcohol $\left(\mathbf{3}-\mathbf{d}_{\mathbf{2}} \mathbf{1 , 2}\right)^{31}$ (Table 3, entry 2, and Figures S10 and S11 in

Table 2. Kinetic isotope effect in the hydrogenation of 1 catalyzed by Au nanocatalysts.

\begin{tabular}{ccccccc}
\hline & & \multicolumn{5}{c}{$k_{\mathrm{H}} / k_{\mathrm{D}}{ }^{[a]}$} \\
\cline { 3 - 7 } Entry & \multirow{2}{*}{ Catalyst } & $273 \mathrm{~K}$ & $323 \mathrm{~K}$ & $348 \mathrm{~K}$ & $373 \mathrm{~K}$ & $423 \mathrm{~K}$ \\
\hline 1 & $\mathrm{Au} / \mathrm{\gamma}-\mathrm{Al}_{2} \mathrm{O}_{3}$ & 1.3 & 1.2 & 1.3 & 1.5 & 1.3 \\
2 & $\mathrm{Au} / \mathrm{M} 1$ & 2.5 & 1.9 & 1.4 & 1.5 & 1.4 \\
3 & $\mathrm{Au} / \mathrm{M} 2$ & 2.9 & 2.1 & 1.6 & 1.5 & 1.3 \\
\hline
\end{tabular}

${ }^{[a]}$ Calculated from Table 2. the ESI). As the hydrogenation of $\mathbf{3}$ provided only $\mathbf{2}$ by using the $\mathrm{Au} / \mathrm{V}-\mathrm{Al}_{2} \mathrm{O}_{3}$ catalyst (Scheme 2a), the generation of the corresponding enol followed by isomerization to aldehyde via a keto-enol equilibrium could be corroborated (Scheme 2b). Interestingly, the $\mathrm{C}=\mathrm{O}$ double bond was hydrogenated only when conjugated to the $\mathrm{C}=\mathrm{C}$ group, probably by means of the $\eta^{4}$ adsorption mode. ${ }^{32}$, $33 \mathrm{In}$ this scenario, an ionic hydrogenation mechanism could occur in which $\gamma-\mathrm{Al}_{2} \mathrm{O}_{3}$ cooperates with the Au surface sites, generating the heterolytic activation of $\mathrm{H}_{2}$ and the transference of one proton to the carbonyl group of $\mathbf{1}$ with formation of the Au-hydride (Scheme 3a). ${ }^{34,} 35$

Moreover, higher amounts of $\mathbf{2 - d}_{\mathbf{2}} \mathbf{d}^{\mathbf{3}, 4}$ using the $\mathrm{Au}$ nanocatalysts confined in the IL Au/M1 and Au/M2 (87-94\%) (Table 3, entries 4 and 6 and Figures S12-S15 in the ESI) indicate the following two possible hydrogenation pathways: (i) the occurrence of 1,4-addition of $\mathrm{H}_{2}$ followed by isomerization of

\begin{tabular}{|c|c|c|c|c|}
\hline T & $\underset{\mathrm{H}_{2} \text { or } \mathrm{D}_{2}}{\stackrel{\text { Au-catalyst }}{\text { anisole }}}$ & & 3,4 & $2^{2,3}$ \\
\hline \multirow{2}{*}{ Entry ${ }^{[a]}$} & \multirow{2}{*}{ Catalyst } & \multicolumn{3}{|c|}{ Selectivity/ \%[b] } \\
\hline & & $2-d_{0}$ & $2-d_{2} 3,4$ & $2-d_{2}{ }^{2,3}$ \\
\hline 1 & \multirow{2}{*}{$\mathrm{Au} / \mathrm{Y}-\mathrm{Al}_{2} \mathrm{O}_{3}$} & 98 & - & - \\
\hline $2^{[c]}$ & & - & 27 & 72 \\
\hline 3 & \multirow{2}{*}{$\mathrm{Au} / \mathrm{M} 1$} & 96 & - & - \\
\hline $4^{[c]}$ & & - & 87 & 12 \\
\hline 5 & \multirow{2}{*}{$\mathrm{Au} / \mathrm{M} 2$} & 97 & - & - \\
\hline $6^{[c]}$ & & - & 94 & 5 \\
\hline
\end{tabular}

[a] Reaction conditions: $\mathrm{Au}(0.5 \mu \mathrm{mol}), 1 / \mathrm{Au}=4000$, anisole $(10 \mathrm{~mL}), 2.5 \mathrm{MPa}$ of $\mathrm{H}_{2}$, $273 \mathrm{~K}$, and $250 \mathrm{rpm}$; [b]Selectivity determined by gas chromatography (GC) and nuclear magnetic resonance (NMR) analyzes at conversions of approximately $5 \%$; ${ }^{[c]}$ By using $2.5 \mathrm{MPa}$ of $\mathrm{D}_{2}$. 
<smiles>O=CCCc1ccccc1</smiles>
3

(a)

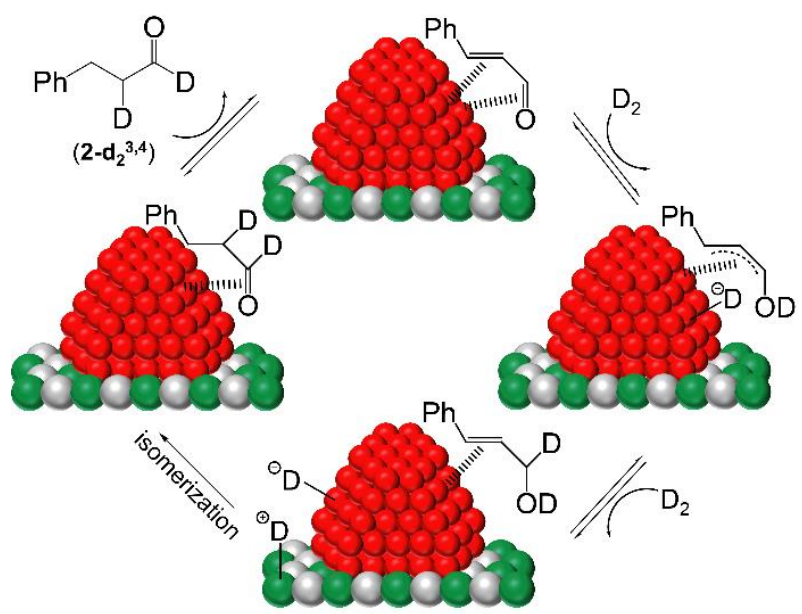

(b)

Scheme 2. Isomerization of (a) $\mathbf{3}$ and (b) $\mathbf{3}-\mathbf{d}_{\mathbf{2}}$ catalyzed by $\mathrm{Au} / \mathrm{\gamma}-\mathrm{Al}_{2} \mathrm{O}_{3}$. Reaction conditions: $\mathrm{Au}(0.5 \mu \mathrm{mol})$, substrate/Au $=1000$, anisole $(10 \mathrm{~mL}), 2.5 \mathrm{MPa}$ of $\mathrm{H}_{2}$ or $\mathrm{D}_{2}, 273$ $\mathrm{K}$, and $250 \mathrm{rpm}$. Adapted from reference 18.

the enol formed, or (ii) a 3,4-addition directly to the ethylenic double bond. In addition, conversions below $1 \%$ were obtained $\mathrm{C}=\mathrm{C}$ double bond undergoes hydrogenation solely when conjugated with the $\mathrm{C}=\mathrm{O}$ group, which implies a preferential $\eta^{4}$ in the hydrogenation of $\mathbf{2}$ and $\mathbf{3}$ by both $\mathrm{Au} / \mathrm{M} \mathbf{1}$ and $\mathrm{Au} / \mathbf{M} 2$ catalysts. As in the case of $\mathrm{Au} / \gamma-\mathrm{Al}_{2} \mathrm{O}_{3}$, these facts indicate that adsorption pathway. ${ }^{32,33}$ Here, there is the possible presence of dissociative chemisorption of the $\mathrm{H}_{2}$ mechanism with the formation of $\mathrm{H}$ atoms in bridge positions, which share the low coordinated Au surface atoms without substantially affecting the Au-Au distances (Scheme 3b). ${ }^{36,37}$ These higher KIE values and higher amounts of $\mathbf{2}-\mathbf{d}_{\mathbf{2}} \mathbf{3 , \mathbf { 4 }}$ could suggest the possible involvement of a tunneling mechanism in these restricted and confined spaces. ${ }^{38,} 39$ Although this effect is rarely observed, the IL environment probably allows the hydrogen to move from one side of the energy barrier to the other. Further evidence of the probable involvement of tunneling are the shape of the Arrhenius plots, the apparent activation energies $\left(E_{\mathrm{a} \text {-app }}\right)$, and the pre-exponential factor $(A)$ values for the hydrogenation and deuteration reactions (see below). ${ }^{12,13}$

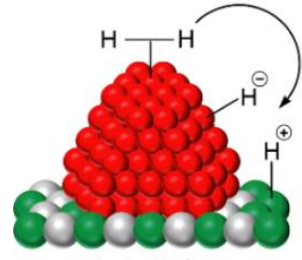

$\mathrm{Au} / \mathrm{y}-\mathrm{Al}_{2} \mathrm{O}_{3}$

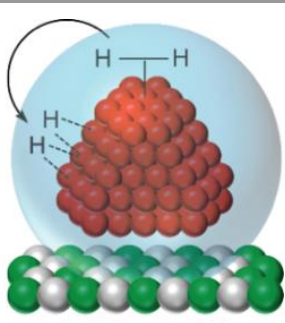

$\mathrm{Au} / \mathrm{M} 1$ or $\mathrm{Au} / \mathrm{M} 2$

(b)
Scheme 3. Proposed mechanisms for the (a) heterolytic and (b) homolytic activation of hydrogen by confined Au nanocatalysts. Adapted from reference 18 .
Based on these deuterium labelling and kinetics experiments, and including the desorption of saturated carbonyl compound $\mathbf{2}$ as an additional step to the classic Horiuti-Polanyi mechanism, ${ }^{40}$ two different pathways are possible in the hydrogenation of $\mathbf{1}$. For the hydrogenation of $\mathrm{C}=\mathrm{O}$ by the $\mathrm{Au} / \mathrm{v}-\mathrm{Al}_{2} \mathrm{O}_{3}$ catalyst, the scenario probably involves the following: (i) adsorption of the entire $\mathrm{C}=\mathrm{C}-\mathrm{C}=\mathrm{O}$ system on the Au surface, (ii) the first addition of $\mathrm{H}$ to the $\mathrm{O}$ atom (providing the hydroxyallyl intermediate), and (iii) the second addition of $\mathrm{H}$ to the carbonyl carbon (generating the allyl alcohol), ${ }^{41}$ followed by its isomerization to the saturated aldehyde (Scheme 4a). The second mechanism for the hydrogenation of $\mathrm{C}=\mathrm{C}$ by $\mathrm{Au} / \mathrm{M} \mathbf{1}$ and $\mathrm{Au} / \mathrm{M} 2$ catalysts possibly includes the following: (i) adsorption of the $\mathrm{C}=\mathrm{C}-\mathrm{C}=\mathrm{O}$ group on the $\mathrm{Au}$ surface, (ii) the first addition of $\mathrm{H}$ to the $\mathrm{C}$ attached to the phenyl group (producing the 1-formylphenethyl intermediate), and (iii) the second addition of $\mathrm{H}$ to the second ethylenic carbon (providing the saturated aldehyde) ${ }^{41}$ (Scheme 4b). These observations are in agreement with the fact that, different from group 8-10 metals, AuNP surfaces are saturated with hydrogen, since Au displays an increasing ability to dissociate $\mathrm{H}_{2}$ homolytically and uptakes the $\mathrm{H}_{2}$ with an increase

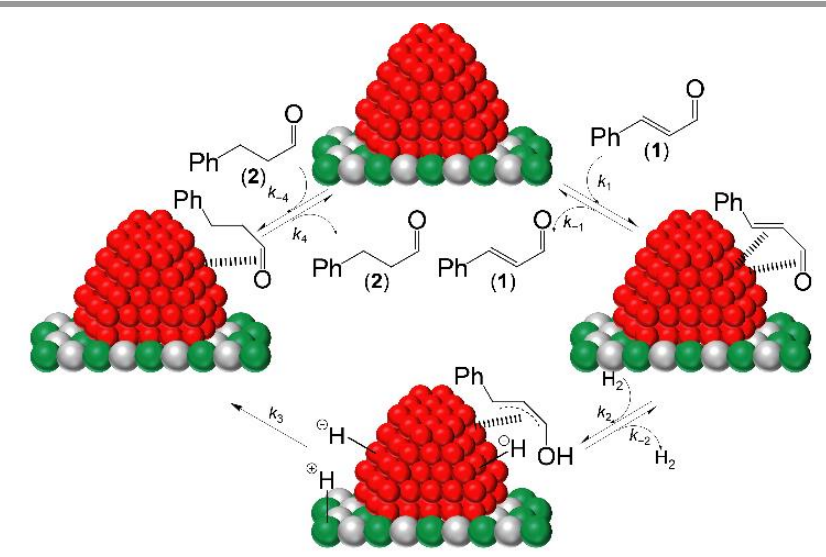

(a)

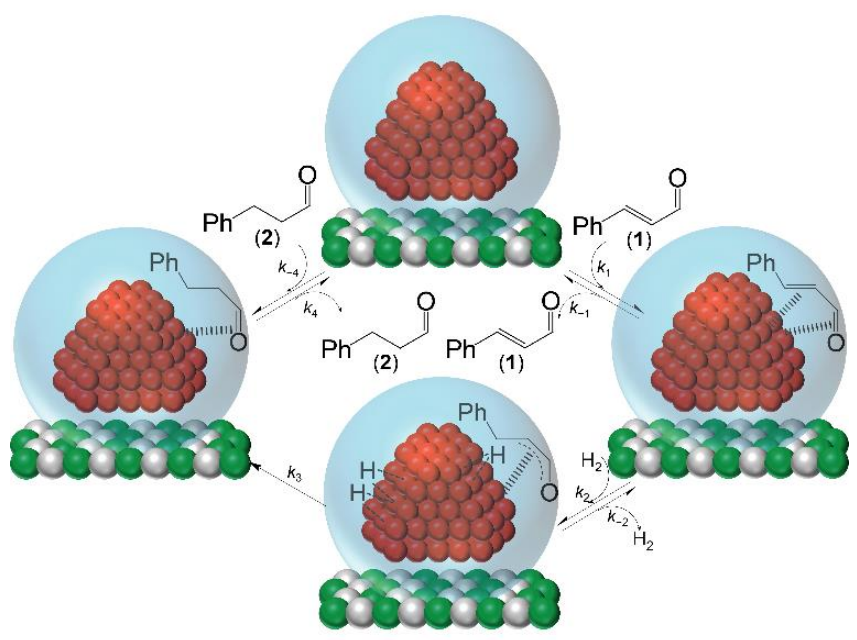

(b)

Scheme 4. Proposed mechanism for the hydrogenation of $\mathbf{1}$ catalyzed by (a) $\mathrm{Au} / \mathrm{\gamma}-\mathrm{Al}_{2} \mathrm{O}_{3}$, and (b) Au/M1 and Au/M2. Adapted from reference 18. 
Table 4. Kinetic and adsorption data for the hydrogenation of 1 catalyzed by confined Au nanocatalysts.

\begin{tabular}{|c|c|c|c|c|c|c|}
\hline \multirow{2}{*}{ Entry } & \multirow{2}{*}{ Catalyst } & \multicolumn{3}{|c|}{$E_{\text {a-app }} / \mathrm{kJ} \mathrm{mol}^{-1}\left[\mathrm{~A}\left(\times 10^{3}\right) / \mathrm{s}^{-1}\right]^{[\mathrm{a}]}$} & \multirow{2}{*}{$\begin{array}{c}\Delta H_{\text {app }} / \\
\mathrm{kJ} \mathrm{mol}^{-1[b]}\end{array}$} & \multirow{2}{*}{$\begin{array}{c}\Delta S_{\text {app }} / \\
\mathrm{J} \mathrm{mol} \mathrm{l}^{-1} \mathrm{~K}^{-1[\mathrm{~b}]}\end{array}$} \\
\hline & & $273-348 \mathrm{~K}$ & $348-423 \mathrm{~K}$ & $273-423 \mathrm{~K}$ & & \\
\hline 1 & \multirow{2}{*}{$\mathrm{Au} / \mathrm{Y}-\mathrm{Al} 2 \mathrm{O} 3$} & $20.9[224]$ & $24.0[737]$ & $22.8[491]$ & -10.7 & -21.8 \\
\hline $2^{[c]}$ & & $21.3[211]$ & $24.1[552]$ & $24.3[597]$ & -9.1 & -20.7 \\
\hline 3 & \multirow{2}{*}{$\mathrm{Au} / \mathrm{M} 1$} & $39.2[149,529]$ & $20.1[227]$ & $33.1[13,565]$ & -13.6 & -31.3 \\
\hline $4^{[c]}$ & & $44.8[685,048]$ & $20.2[170]$ & $37.2[33,666]$ & -11.9 & -25.9 \\
\hline 5 & \multirow{2}{*}{$\mathrm{Au} / \mathrm{M} 2$} & $34.8[22,298]$ & $20.6[178]$ & $30.4[3,775]$ & -13.9 & -32.6 \\
\hline $6^{[c]}$ & & $41.0[114,033]$ & 23.5 [303] & $35.6[13,046]$ & -12.4 & -27.8 \\
\hline
\end{tabular}

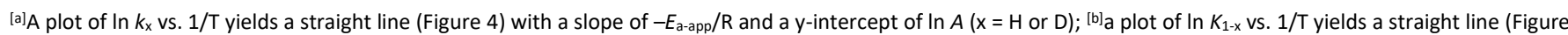
5) with a slope of $-\Delta H_{a p p} / R$ and a y-intercept of $\Delta S_{\text {app }} / R(x=H$ or $D) ; 42[c]$ by using $D_{2}$.

in reaction temperature. ${ }^{43}$

A plot of the natural log of $k_{\mathrm{H}}$ and $k_{\mathrm{D}}$ against the inverse of reaction temperature enabled the estimation of the $E_{\mathrm{a} \text {-app }}$ for the hydrogenation and deuteration of 1 catalyzed by $\mathrm{Au} / \mathrm{\gamma}$ $\mathrm{Al}_{2} \mathrm{O}_{3}, \mathrm{Au} / \mathrm{M} 1$, and $\mathrm{Au} / \mathrm{M} 2$ (Table 4 and Figure 4). The Arrhenius plots obtained for the $\mathrm{Au} / \mathrm{\gamma}-\mathrm{Al}_{2} \mathrm{O}_{3}$ catalyst exhibited close $E_{\text {a-app }}$ values at low and high temperature ranges in both hydrogenation and deuteration reactions (20.9-24.0 kJ mol-1 and 21.3-24.1 kJ mol-1, respectively) (Table 4, entries 1 and 2, and Figure 4a). Furthermore, the fraction of molecules that possessed enough kinetic energy to react, expressed by $A$, displayed relatively similar behavior, since the values achieved were in the same order of magnitude $\left(224-737 \times 10^{3} \mathrm{~s}^{-1}\right.$ for $\mathrm{H}_{2}$ and 211-552 $\times 10^{3} \mathrm{~s}^{-1}$ for $D_{2}$, Table 4, entries 1 and 2). Interestingly, for $\mathrm{Au} / \mathrm{M} \mathbf{1}$ and $\mathrm{Au} / \mathbf{M} 2$ catalysts, the Arrhenius plots exhibited a convex curve within the studied temperature range (Figures $4 \mathrm{~b}$ and $4 \mathrm{c}$ ). Remarkably, this fact may suggest the involvement of the tunneling effect ${ }^{12}, 13$ with a change in the reaction pathway and, consequently, the formation of a different product. ${ }^{10}$ By using these catalysts at lower temperatures (273-348 K), the intermediate 1-formylphenethyl predominates both in hydrogenation ( $A$ of $149,529 \times 10^{3}$ and $22,298 \times 10^{3} \mathrm{~s}^{-1}$ ) and deuteration ( $A$ of $685,048 \times 10^{3}$ and $\left.114,033 \times 10^{3} \mathrm{~s}^{-1}\right)$ with higher $E_{\mathrm{a}-a p p}$ values when compared to the $\mathrm{Au} / \gamma-\mathrm{Al}_{2} \mathrm{O}_{3}$ catalyst $\left(39.2\right.$ and $34.8 \mathrm{~kJ} \mathrm{~mol}^{-1}$ for the hydrogenation and 44.8 and $41.0 \mathrm{~kJ} \mathrm{~mol}^{-1}$ for the deuteration) (Table 4, entries 3-6, and Figures $4 \mathrm{~b}$ and $4 \mathrm{c}$, red dash). On the other hand, as the temperature increases (348-423 K), the metastable intermediate dissociates and becomes non-reactive (smaller $A$ values by two-to-three orders of magnitude: $170-$ $303 \times 10^{3} \mathrm{~s}^{-1}$ ), which disturbs the reaction rates and leads to lower $E_{\mathrm{a}-\mathrm{app}}$ values between 20.1 and $23.5 \mathrm{~kJ} \mathrm{~mol}^{-1}$ (Table 4, entries 3-6, Figures $4 \mathrm{~b}$ and $4 \mathrm{c}$, blue dash). The $E_{\mathrm{a} \text {-app }}$ values at low temperatures were comparable to those reported for $\mathrm{Pd}$ and AuNPs on similar supports $\left(32\right.$ and $29 \mathrm{~kJ} \mathrm{~mol}^{-1}$, respectively), but the $E_{\mathrm{a} \text {-app }}$ values at high temperatures ( $20 \mathrm{~kJ}$ $\left.\mathrm{mol}^{-1}\right)$ were much higher when compared to $\mathrm{Au}\left(9 \mathrm{~kJ} \mathrm{~mol}^{-1}\right)$ and were slightly lower than $\mathrm{Pd}\left(24 \mathrm{~kJ} \mathrm{~mol}^{-1}\right) .{ }^{18,19}$ Negative apparent enthalpies

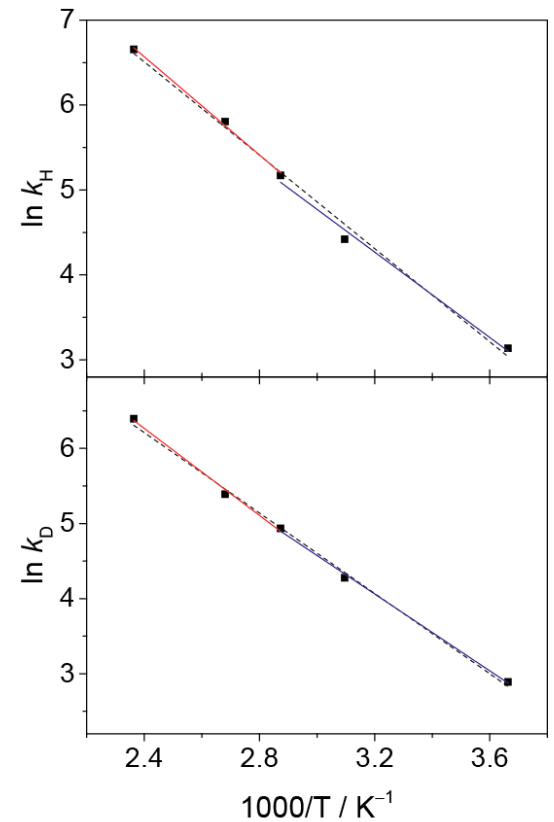

(a)

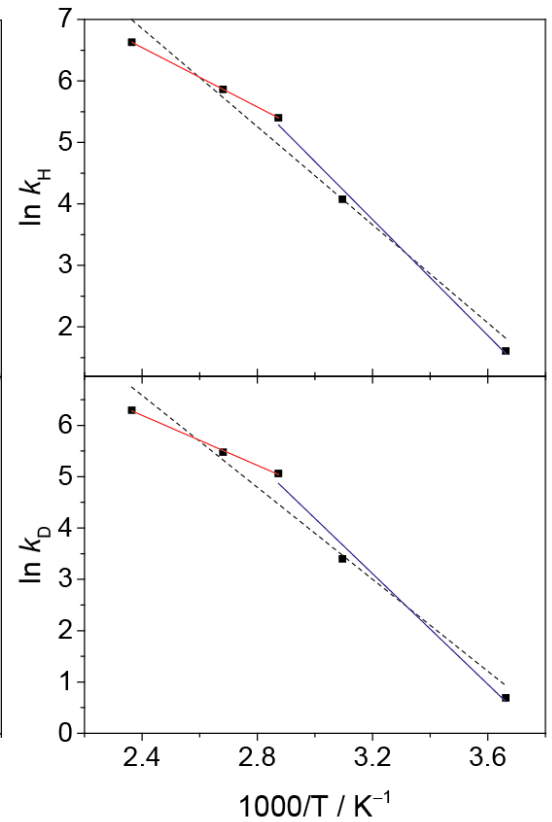

(b)

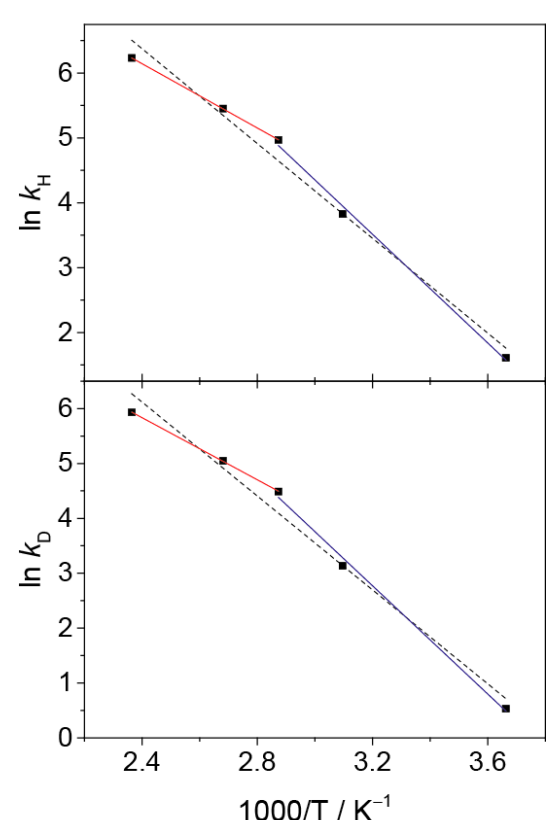

(c)

Figure 4. Arrhenius plots of the hydrogenation and deuteration of 1 catalyzed by (a) $\mathrm{Au} / \mathrm{\gamma}^{-}-\mathrm{Al}_{2} \mathrm{O}_{3}$, (b) $\mathrm{Au} / \mathrm{M} 1$, and (c) $\mathrm{Au} / \mathrm{M} 2$. 


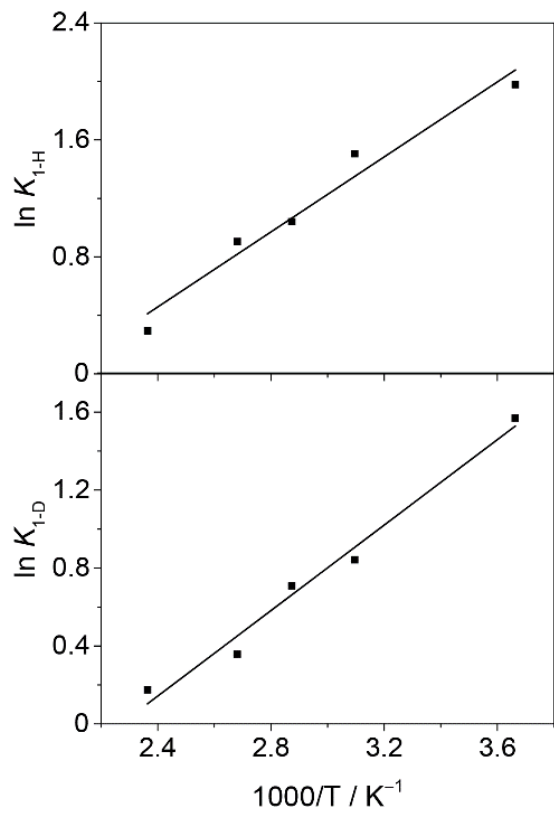

(a)

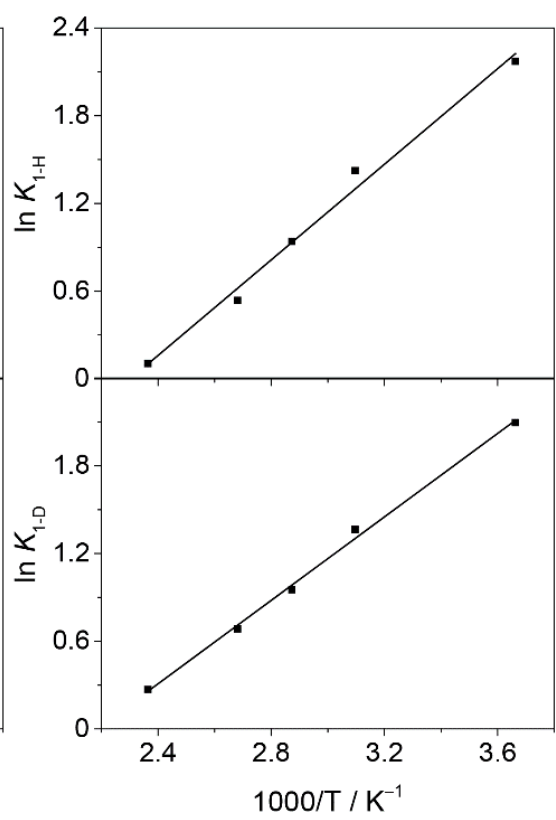

(b)

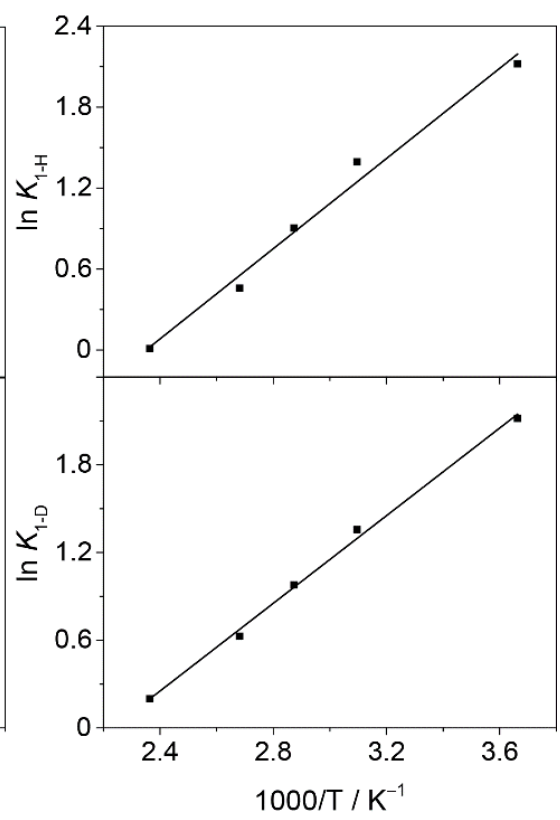

(c)

Figure 5. Van't Hoff plots of the hydrogenation and deuteration of 1 catalyzed by (a) $\mathrm{Au} / \mathrm{v}^{-}-\mathrm{Al}_{2} \mathrm{O}_{3}$, (b) $\mathrm{Au} / \mathrm{M} \mathbf{1}$, and (c) $\mathrm{Au} / \mathrm{M} 2$.

$\left(\Delta H_{\text {app }}\right)$ were observed in the Van't Hoff plots for the adsorption of 1 for all catalysts, with higher values when using $\mathrm{Au} / \gamma-\mathrm{Al}_{2} \mathrm{O}_{3}$ (-10.7 and $\left.-9.1 \mathrm{~kJ} \mathrm{~mol}^{-1}\right)$ and lower values for $\mathrm{Au} / \mathrm{M1}$ and Au/M2 (-13.9 to $-11.9 \mathrm{~kJ} \mathrm{~mol}^{-1}$ ) (Table 4, Figure 5, and Table S9 in the ESI). The same trend was detected for the apparent entropy $\left(\Delta S_{\text {app }}\right.$, related to the adsorption of 1 , Table 4$)$, which suggests a reduction in the number of microstates in the nanoconfined environment in the $\mathrm{Au} / \mathrm{IL}-\mathrm{hybrid} \gamma-\mathrm{Al}_{2} \mathrm{O}_{3}(\mathrm{Au} / \mathrm{M} \mathbf{1}$ and $\mathrm{Au} / \mathrm{M2}$ ) as compared to the non-hybrid catalyst $\left(\mathrm{Au} / \mathrm{\gamma}-\mathrm{Al}_{2} \mathrm{O}_{3}\right)$. Besides the convex shapes displayed by the Arrhenius plots, there were two other factors that could be associated with a contribution from the tunneling effect: differences between the apparent activation energies of the deuteration and hydrogenation reactions $\left(E_{\mathrm{a} \text {-app }}{ }^{\mathrm{D}}-E_{\mathrm{a} \text {-app }}{ }^{\mathrm{H}}\right)$ above $5 \mathrm{~kJ} \mathrm{~mol}^{-1}$ associated with ratios higher than 2 for their respective preexponential factors $\left(A_{D} / A_{H}\right) \cdot{ }^{13,15}$

Because of this, and based on the deuterium labelling and kinetics experiments by using any of the catalysts at high temperatures $(348-423 \mathrm{~K})$, these parameters were too far below those required for the tunneling effect to have significance (Table 5, entries 1-3). Interestingly, at low temperatures $(273-348 \mathrm{~K})$, the values of 5.6 and $6.2 \mathrm{~kJ} \mathrm{~mol}^{-1}$ related to the $E_{\mathrm{a}-\mathrm{app}}{ }^{\mathrm{D}}-E_{\mathrm{a}-\mathrm{app}}{ }^{\mathrm{H}}$ and $A^{\mathrm{D}} / A^{\mathrm{H}}$ ratios of 4.6 and 5.1 were obtained only by the IL-confined AuNPs (Au/M1 and
$\mathrm{Au} / \mathrm{M} 2$ catalysts, respectively), which are significantly away from the tunneling/nontunneling limit (Table 5, entries 2 and 3). Thus, these facts offer robust indications that the tunneling correction could be considerable in these IL-hybrid $y-\mathrm{Al}_{2} \mathrm{O}_{3}$ environments.

\section{Conclusions}

In summary, AuNPs in direct contact with an oxide support the induction of the heterolytic cleavage of $\mathrm{H}_{2}$, whereas AuNPs located preferentially away from the oxide support, i.e., in the IL cage, homolytically activate the $\mathrm{H}_{2}$. These IL-nanocontainers minimize the interaction between $\mathrm{Au}$ and $\gamma-\mathrm{Al}_{2} \mathrm{O}_{3}$, thus exchanging the hydrogen activation mechanism. The hydrogenation pathways are determined by the movement of the IL layer, which rearranges and allows the hydrogen to tunnel almost instantaneously. Most importantly, in these AuNPs/IL cages, high KIEs values, convex Arrhenius plots, and $E_{\mathrm{a}-\mathrm{app}} \mathrm{D}-E_{\mathrm{a}-}$ ${ }_{\text {app }}{ }^{\mathrm{H}}$ considerably above $5 \mathrm{~kJ} \mathrm{~mol}^{-1}$ associated with $A^{\mathrm{D}} / A^{\mathrm{H}}$ ratios greater than 2 strongly suggest the possible involvement of a tunneling effect. For these reasons, this study suggests that in dynamic confined spaces the tunneling pathway can operate more often than what is generally expected.

Table 5. Contribution from tunneling in the hydrogenation of 1 catalyzed by confined Au nanocatalysts.

\begin{tabular}{|c|c|c|c|c|c|}
\hline \multirow{2}{*}{ Entry ${ }^{[a]}$} & \multirow{2}{*}{ Catalyst } & \multicolumn{2}{|c|}{$E_{\text {a-app }}{ }^{\mathrm{D}}-E_{\mathrm{a} \text {-app }}{ }^{\mathrm{H}} / \mathrm{kJ} \mathrm{mol}^{-1}$} & \multicolumn{2}{|c|}{$A^{\mathrm{D}} / A^{\mathrm{H}}$} \\
\hline & & $273-348 \mathrm{~K}$ & $348-423 \mathrm{~K}$ & $273-348 \mathrm{~K}$ & $348-423 \mathrm{~K}$ \\
\hline 1 & $\mathrm{Au} / \nu-\mathrm{Al}_{2} \mathrm{O}_{3}$ & 0.4 & 0.1 & 0.9 & 0.7 \\
\hline 2 & $\mathrm{Au} / \mathrm{M} 1$ & 5.6 & 0.1 & 4.6 & 0.7 \\
\hline 3 & $\mathrm{Au} / \mathrm{M} 2$ & 6.2 & 2.9 & 5.1 & 1.7 \\
\hline
\end{tabular}

[a]Calculated from Table 3. 


\section{Experimental}

\section{General}

All syntheses were performed using standard Schlenk techniques under an argon atmosphere. Chemicals were purchased from Sigma-Aldrich and used without further purification. The ILs were prepared employing the original procedures described elsewhere. ${ }^{44} \mathrm{H}_{2}(>99.999 \%)$ and $\mathrm{D}_{2}$ (D> 99.8\%) were purchased from White-Martins and Cambridge Isotope Laboratories, Inc, respectively. Petrobras provided the $\gamma-\mathrm{Al}_{2} \mathrm{O}_{3}$ used in this study. Synthesis and characterization of the IL-hybrid $\gamma-\mathrm{Al}_{2} \mathrm{O}_{3}$ supports ( $\mathbf{M} 1$ and $\mathbf{M} 2$ ) were as reported elsewhere. ${ }^{16,}{ }^{17}$ The ${ }^{13} \mathrm{C}$ and ${ }^{29} \mathrm{Si}$ solid-state cross-polarization magic angle spinning nuclear magnetic resonance (CP-MAS NMR) spectra were performed using a Bruker $400 \mathrm{MHz}$ spectrometer at the CNANO/UFRGS. Fourier transform infrared (FT-IR) spectra were obtained using an ABB FTLA 2000 instrument with a resolution of $4 \mathrm{~cm}^{-1}$ with 128 cumulative scans. The $\mathrm{N}_{2}$-physisorption of the catalysts, previously degassed at $373 \mathrm{~K}$ under vacuum for $3 \mathrm{~h}$, were obtained using Tristar 3020 Micromeritics equipment. Specific surface areas were determined by the Brunauer-Emmett-Teller (BET) multipoint method, and the average pore size was obtained by the Barrett-Joyner-Halenda (BJH) method. Au content was determined by X-ray fluorescence (XRF) carried out using a Shimadzu XRF-1800 sequential spectrometer. Samples were prepared in $\mathrm{KBr}$, and calibration was performed using bromine as an internal standard. Rutherford backscattering spectrometry (RBS) measurements were carried out in a $3 \mathrm{MV}$ Tandetron accelerator using a $\mathrm{He}^{+}$ion beam of $1.5 \mathrm{MeV}$ at IF/UFRGS. The Si surface barrier detector was positioned at a scattering angle of $165^{\circ}$. The X-ray diffraction (XRD) analyses were carried out using a Philips X'Pert MPD diffractometer with Bragg-Brentano geometry using a graphite curved crystal with $\mathrm{Cu} \mathrm{K} \alpha$ X-ray radiation (1.5406 Å). Transmission electron microscopy (TEM) was performed on a JEOL-JEM 1200ExII electron microscope operating at $120 \mathrm{kV}$. The samples were prepared by the slow evaporation of a drop of each colloidal solution deposited under an argon atmosphere onto a holey carbon-coated copper grid. XPS measurements were performed using a Kratos AXIS UItra DLD instrument. The analysis chamber pressure during the measurements was greater than $0.5 \mu \mathrm{Pa}$. Wide energy range survey scans were collected at a pass energy of $80 \mathrm{eV}$ in hybrid slot lens mode with a step size of $0.5 \mathrm{eV}$. Highresolution data on the $\mathrm{Au} 4 \mathrm{f}, \mathrm{Au} \mathrm{VB}, \mathrm{Al} 2 \mathrm{p}, \mathrm{Cl} 2 \mathrm{p}$, and $\mathrm{F}$ 1s photoelectron peaks were collected at a pass energy of $20 \mathrm{eV}$ over energy ranges suitable for each peak, with collection times of $5 \mathrm{~min}$ and step sizes of $0.1 \mathrm{eV}$. The X-ray source was a monochromated Al Ka emission run at $10 \mathrm{~mA}$ and $12 \mathrm{kV}$ (120 $W)$. The high-resolution spectra were analyzed using a Lorentzian asymmetric line shape convoluted with a Gaussian function for each chemical component. The high-resolution data was charge corrected to the reference peak of the $\mathrm{Al} 2 \mathrm{p}$ signal of $\gamma-\mathrm{Al}_{2} \mathrm{O}_{3}$ at $74.5 \mathrm{eV}$.

\section{Preparation of the AuNPs}

As a general procedure for AuNP preparation by sputtering deposition, $1.0 \mathrm{~g}$ of each support $\left(\gamma-\mathrm{Al}_{2} \mathrm{O}_{3}, \mathbf{M} 1\right.$, and $\left.\mathbf{M} 2\right)$ was placed into a conical aluminum flask inside a vacuum chamber containing an electromagnetic oscillator with variable controlled frequency, which allowed for constant movement of the conical flask. Then, the chamber was closed, its pressure was lowered to a base pressure of $0.4 \mathrm{~Pa}$, and the supports were evacuated at this pressure for $4 \mathrm{~h}$. Then, the vacuum chamber was placed under a sputtering working pressure of $0.4 \mathrm{kPa}$ by adding argon flow. The supports were continuously homogenized by revolving the aluminum flask at a vibration frequency of $24 \mathrm{~Hz}$. The Au was sputtered onto the revolving support at $35 \mathrm{~mA}$ of discharge current for $4.5 \mathrm{~min}$ to give the $\mathrm{Au} / \mathrm{v}-\mathrm{Al}_{2} \mathrm{O}_{3}, \mathrm{Au} / \mathrm{M} 1$, and $\mathrm{Au} / \mathrm{M} 2$ catalysts. After deposition, the chamber was vented with nitrogen and the red powders were recovered and stored under argon atmosphere for further characterization and application.

\section{Hydrogenation Reactions}

As a general procedure for the hydrogenation reactions, the catalyst $(0.5 \mu \mathrm{mol} A u)$, substrate $(1 / \mathrm{Au}=1000)$, and solvent $(10$ $\mathrm{mL}$ of anisole) were placed in a $25 \mathrm{~mL}$ stainless steel reactor. The reaction vessel was pressurized with $2.5 \mathrm{MPa}$ of $\mathrm{H}_{2}$ and warmed to the desired temperature. Aliquots of $25 \mu \mathrm{L}$ were regularly taken during the reaction. After the reaction time, the reactor was cooled to room temperature and depressurized. The conversion and selectivity were determined by GC and NMR analyzes of the reaction samples. GC analyses of the reaction samples were run with an Agilent Technologies GC System 6820 with an injector and detector (FID) temperature of $533 \mathrm{~K} . \mathrm{N}_{2}$ was the carrier $\left(1 \mathrm{~mL} \mathrm{~min}^{-1}\right)$, the column head pressure was $70 \mathrm{kPa}$, the temperature program was from $313 \mathrm{~K}(10 \mathrm{~min})$ to $523 \mathrm{~K}$ at a heating rate of $10 \mathrm{~K} \mathrm{~min}^{-1}$, and a DB-17 column (30 m $\times 0.25$ $\mathrm{mm} \times 0.25 \mu \mathrm{m}$ ) was used. ${ }^{1} \mathrm{H}$ and ${ }^{2} \mathrm{H}$ NMR analyses of the samples obtained by $D_{2}$ reduction of 1 catalyzed by AuNPs were performed using a Varian $400 \mathrm{MHz}$ spectrometer at CNANO/UFRGS. The incorporation of $D$ in the reaction products was quantified by comparing the ${ }^{1} \mathrm{H}$ and ${ }^{2} \mathrm{H}$ NMR spectra with these obtained from standard samples. The KIEs values were calculated from the slope of hydrogenation/deuteration reaction rates vs. time at conversions of approximately $5 \%$ by using a modified Langmuir-Hinshelwood model (Equation 1). ${ }^{25}$, ${ }^{26}$ Plots of $\ln k_{\mathrm{x}}$ and $\ln K_{1-\mathrm{x}}$ vs. $1 / T$ yield straight lines with a slope of $-E_{\text {a-app }} / R$ and a $y$-intercept of $\ln A$ and with a slope of $-\Delta H_{\text {app }} / R$ and a y-intercept of $\Delta S_{\mathrm{app}} / \mathrm{R}$, respectively $(\mathrm{x}=\mathrm{H}$ or $\mathrm{D}) .{ }^{42}$

\section{Conflicts of interest}

There are no conflicts to declare.

\section{Acknowledgements}

The authors are thankful to CAPES, FAPERGS, and CNPq-INCT for financial support. 


\section{References}

1. S. H. Leenders, R. Gramage-Doria, B. de Bruin and J. N. Reek Chem. Soc. Rev., 2015, 44, 433-448.

2. J. Xiao, X. Pan, S. Guo, P. Ren and X. Bao, J. Am. Chem. Soc., 2015, 137, 477-482.

3. A. Weilhard, G. Abarca, J. Viscardi, M. H. G. Prechtl, J. D. Scholten, F. Bernardi, D. L. Baptista and J. Dupont, ChemCatChem, 2017, 9, 204-211.

4. D. Bedeaux, S. Kjelstrup, L. Zhu and G. J. Koper, Phys. Chem. Chem. Phys., 2006, 8, 5421-5427.

5. D. P. Sheehan, Phys. Rev. E, 2013, 88, 032125.

6. L. Zhu and G. Frens, J. Phys. Chem. B, 2006, 110, 18307-18312.

7. S. Jakubith, H. H. Rotermund, W. Engel, A. von Oertzen and G. Ertl, Phys. Rev. Lett., 1990, 65, 3013-3016.

8. E. Rabani, D. R. Reichman, P. L. Geissler and L. E. Brus, Nature, 2003, 426, 271-274.

9. H. Tanaka, J. Phys.: Condens. Matter, 2000, 12, R207-R264.

10. P. R. Schreiner, J. Am. Chem. Soc., 2017, 139, 15276-15283.

11. A. Datta, D. A. Hrovat and W. T. Borden, J. Am. Chem. Soc., 2008, 130, 2726-2727.

12. H.-H. Limbach, J. Miguel Lopez and A. Kohen, Philos. Trans. R. Soc. Lond. B Biol. Sci., 2006, 361, 1399-1415.

13. R. P. Bell, The Tunnel Effect in Chemistry, Springer US 1980.

14. M. Schäfer, K. Peckelsen, M. Paul, J. Martens, J. Oomens, G. Berden, A. Berkessel and A. J. H. M. Meijer, J. Am. Chem. Soc. 2017, 139, 5779-5786.

15. J. E. Baldwin and V. P. Reddy, Journal of the American Chemical Society, 1988, 110, 8223-8228.

16. L. Foppa, L. Luza, A. Gual, D. E. Weibel, D. Eberhardt, S. R. Teixeira and J. Dupont, Dalton Trans., 2015, 44, 2827-2834.

17. L. Luza, A. Gual, D. Eberhardt, S. R. Teixeira, S. S. X. Chiaro and J. Dupont, ChemCatChem, 2013, 5, 2471-2478.

18. L. Luza, C. P. Rambor, A. Gual, J. Alves Fernandes, D. Eberhardt and J. Dupont, ACS Catal., 2017, 7, 2791-2799.

19. L. Luza, C. P. Rambor, A. Gual, F. Bernardi, J. B. Domingos, T. Grehl, P. Brüner and J. Dupont, ACS Catal., 2016, 6, 6478 6486.

20. M. Sobota, M. Happel, M. Amende, N. Paape, P. Wasserscheid, M. Laurin and J. Libuda, Adv. Mater., 2011, 23 2617-2621.

21. C. Sievers, O. Jimenez, T. E. Müller, S. Steuernagel and J. A. Lercher, J. Am. Chem. Soc., 2006, 128, 13990-13991.

22. S. Caporali, U. Bardi and A. Lavacchi, J. Electron. Spectrosc. Relat. Phenom., 2006, 151, 4-8.

23. H. Zhang and H. Cui, Langmuir, 2009, 25, 2604-2612.

24. J. Zhu, Y. Shen, A. Xie, L. Qiu, Q. Zhang and S. Zhang, J. Phys. Chem. C, 2007, 111, 7629-7633.

25. A. P. Umpierre, E. de Jesús and J. Dupont, ChemCatChem, 2011, 3, 1413-1418.

26. K.-Q. Sun, Y.-C. Hong, G.-R. Zhang and B.-Q. Xu, ACS Catal., 2011, 1, 1336-1346.

27. S. Fountoulaki, V. Daikopoulou, P. L. Gkizis, I. Tamiolakis, G. S. Armatas and I. N. Lykakis, ACS Catal., 2014, 4, 3504-3511.

28. L. Luza, A. Gual, C. P. Rambor, D. Eberhardt, S. R. Teixeira, F. Bernardi, D. L. Baptista and J. Dupont, Phys. Chem. Chem. Phys., 2014, 16, 18088-18091.
29. P. Liu, Y. Zhao, R. Qin, S. Mo, G. Chen, L. Gu, D. M. Chevrier, P. Zhang, Q. Guo, D. Zang, B. Wu, G. Fu and N. Zheng, Science, 2016, 352, 797

30. C. A. Bunton, F. Nome, F. H. Quina and L. S. Romsted, Accounts of Chemical Research, 1991, 24, 357-364.

31. A. Chambers, S. David Jackson, D. Stirling and G. Webb, J. Catal., 1997, 168, 301-314.

32. A. H. Virgili, L. Luza, J. A. Fernandes, T. M. H. Costa, E. W. de Menezes and E. V. Benvenutti, Catal. Commun., 2018, 116, 32 37.

33. P. Claus, Top. Catal., 1998, 5, 51-62.

34. G. J. Kubas, Chem. Rev., 2007, 107, 4152-4205.

35. M. H. Voges and R. M. Bullock, J. Chem. Soc., Dalton Trans., 2002, 759-770.

36. M. Boronat, F. Illas and A. Corma, J. Phys. Chem. A, 2009, 113, 3750-3757.

37. M. Boronat, P. Concepción and A. Corma, J. Phys. Chem. C, 2009, 113, 16772-16784.

38. M. Jan and K. Johannes, Angew. Chem. Int. Ed., 2016, 55 5400-5413.

39. T. Hama, H. Ueta, A. Kouchi and N. Watanabe, Proc. Natl. Acad. Sci., 2015, 112, 7438-7443.

40. B. Mattson, W. Foster, J. Greimann, T. Hoette, N. Le, A. Mirich, S. Wankum, A. Cabri, C. Reichenbacher and E. Schwanke, J. Chem. Educ., 2013, 90, 613-619.

41. D. Loffreda, F. Delbecq, F. Vigné and P. Sautet, Angewandte Chemie International Edition, 2005, 44, 5279-5282.

42. R. H. Petrucci, F. G. Herring, J. D. Madura and C. Bissonnette, General Chemistry: Principles and Modern Applications, Pearson Prentice Hall 2010.

43. E. Bus, J. T. Miller and J. A. van Bokhoven, J. Phys. Chem. B, 2005, 109, 14581-14587.

44. S. Einloft, F. K. Dietrich, R. F. De Souza and J. Dupont, Polyhedron, 1996, 15, 3257-3259. 